\title{
The Basis for Diminished Functional Recovery after Delayed Peripheral Nerve Repair
}

\author{
Tessa Gordon, Neil Tyreman, and Mukaila A. Raji \\ Centre for Neuroscience, Department of Medicine and Dentistry, University of Alberta, Edmonton, Alberta T6G 2S2, Canada
}

\begin{abstract}
The postsurgical period during which neurons remain without target connections (chronic axotomy) and distal nerve stumps and target muscles are denervated (chronic denervation) deleteriously affects functional recovery. An autologous nerve graft and cross-suture paradigm in Sprague Dawley rats was used to systematically and independently control time of motoneuron axotomy, denervation of distal nerve sheaths, and muscle denervation to determine relative contributions of each factor to recovery failure. Tibial (TIB) nerve was cross-sutured to common peroneal (CP) nerve via a contralateral $15 \mathrm{~mm}$ nerve autograft to reinnervate the tibialis anterior (TA) muscle immediately or after prolonging TIB axotomy, CP autograft denervation, or TA muscle denervation. Numbers of motoneurons that reinnervated TA muscle declined exponentially from $99 \pm 15$ to asymptotic mean $( \pm$ SE) values of $35 \pm 1,41 \pm 10$, and $13 \pm 5$, respectively. Enlarged reinnervated motor units fully compensated for reduced motoneuron numbers after prolonged axotomy and autograft denervation, but the maximal threefold enlargement did not compensate for the severe loss of regenerating nerves through chronically denervated nerve stumps and for failure of reinnervated muscle fibers to recover from denervation atrophy. Muscle force, weight, and cross-sectional area declined. Our results demonstrate that chronic denervation of the distal stump plays a key role in reduced nerve regeneration, but the denervated muscle is also a contributing factor. That chronic Schwann cell denervation within the nerve autograft reduced regeneration less than after the denervation of both $\mathrm{CP}$ nerve stump and TA muscle, argues that chronic muscle denervation negatively impacts nerve regeneration.
\end{abstract}

\section{Introduction}

Functional recovery is frequently poor after peripheral nerve injury, particularly when nerves are damaged close to the spinal cord and far from their targets. Thus, patients whose traumatic injuries sever large nerve trunks such as the sciatic nerve generally have poor prognosis with little or no functional recovery of their lower limb (Sunderland, 1978). The clinical phenomena are well recognized, but the mechanism(s) for poor nerve regeneration and target reinnervation remain(s) contentious.

Irreversible atrophy of denervated skeletal muscle after nerve injuries has been mistakenly regarded as the cause of poor functional recovery (Sulaiman et al., 2011). Our systematic evaluation in a rat model of prolonged neuronal detachment from target connections after nerve transection (chronic axotomy) and of prolonged denervation of distal nerve stumps (chronic denervation) demonstrated that progressive failure of (1) chronically axotomized motoneurons to regenerate into freshly denervated distal nerve stumps and (2) chronically denervated distal nerve stumps to support nerve regeneration of freshly axotomized neurons account for progressive failure of peripheral nerve regeneration with time and distance (Fu and Gordon, 1995a,b, 1997; You et al., 1997; Sulaiman and Gordon, 2000, 2009; Boyd and Gor-

Received Nov. 24, 2010; revised Jan. 19, 2011; accepted Jan. 30, 2011.

This work was supported by the Canadian Institute of Health Research. We thank Dr. Steven Kemp for his helpful comments on this manuscript.

Correspondence should be addressed to Dr. Tessa Gordon, Department of Surgery, Division of Plastic Surgery, 5549A, The Hospital for Sick Children, 555 University Avenue, Toronto, 0N M5G1X8, Canada. E-mail: tessat.gordon@gmail.com.

DOI:10.1523/JNEUROSCI.6156-10.2011

Copyright $\odot 2011$ the authors $\quad 0270-6474 / 11 / 315325-10 \$ 15.00 / 0$ don, 2003a,b; Gordon et al., 2003; Sulaiman et al., 2005; Furey et al., 2007). We used a retrograde labeling technique to verify that, a year after chronic denervation of the distal nerve stump, $<10 \%$ of motoneurons regenerated their axons into the stump (Sulaiman and Gordon, 2000) and reinnervated muscle (Fu and Gordon, 1995b). The dramatically reduced numbers of regenerating axons reinnervated a maximum number of denervated muscle fibers to form enlarged motor units (Fu and Gordon, 1995b). However, an upper limit of motor unit enlargement when $<25 \%$ of motoneurons remain after partial or complete muscle denervation prevents full recovery of muscle contractile force and weight (Brown and Ironton, 1978; Rafuse et al., 1992; Fu and Gordon, 1995b; Rafuse and Gordon, 1996; Tam et al., 2001; Gordon and Tyreman, 2010).

Our findings of reduced nerve regeneration after chronic denervation of distal nerve stumps could conceivably result from a reported negative impact of the chronically denervated muscles that remain in continuity with the denervated nerve stumps (Bain et al., 2001). This possibility necessitates experiments to evaluate how chronic denervation of distal nerve stumps affects nerve regeneration independently of the effects of chronic muscle denervation. In this study, we used a cross-suture nerve graft paradigm to systematically and individually evaluate the contributions of prolonged axotomy, distal nerve stump denervation, and muscle denervation on the regenerative capacity of peripheral nerves. Our results demonstrate that chronic denervation of the distal stump in and of itself plays a key role in reduced nerve regeneration but that the chronically denervated muscle is also a contributing factor. 


\section{Materials and Methods \\ Animals \\ The experiments were performed on 122 young (120- to 150-d-old) female Sprague Dawley rats with an initial body weight of $220-$ 260 g. Surgery was performed on a total of 90 animals. All surgical procedures were approved by the University of Alberta animal care com- mittee and adhered strictly to the guidelines set by the Canadian Council on Animal Care.}

\section{Surgery}

Cross-union graft repair surgery. Surgery was performed under sterile conditions. Anesthesia was induced with intraperitoneal injection of sodium pentobarbitol $(45 \mathrm{mg} / \mathrm{kg})$. Atropine $(0.1 \mathrm{mg} / \mathrm{kg})$ was also injected to reduce respiratory congestion. In 90 rats, skin incisions were made bilaterally to expose the sciatic nerve and its tibial (TIB) and common peroneal (CP) nerve branches. $\mathrm{TIB}_{\mathrm{p}}-\mathrm{CP}_{\mathrm{g}}-\mathrm{CP}_{\mathrm{d}}$ repair surgery was performed in the right hindlimb to encourage TIB nerve regeneration through a $15 \mathrm{~mm} \mathrm{CP}$ nerve graft $\left(\mathrm{CP}_{\mathrm{g}}\right)$ that bridged between the proximal TIB $\left(\mathrm{TIB}_{\mathrm{p}}\right)$ and distal $\left(\mathrm{CP}_{\mathrm{d}}\right)$ nerve stumps to reinnervate the denervated tibialis anterior (TA) muscle in the flexor muscle compartment (Fig. 1). The remaining 32 rats were not operated on and served as controls.

Immediate nerve graft surgery. For immediate $\mathrm{TIB}_{\mathrm{p}}-\mathrm{CP}_{\mathrm{g}}-\mathrm{CP}_{\mathrm{d}}$ repair surgery, a $15 \mathrm{~mm}$ length of $\mathrm{CP}$ nerve $\left(\mathrm{CP}_{\mathrm{g}}\right)$ was excised from the left hindlimb for nerve grafting in the right hindlimb. TIB and CP nerves were each cut in the right hindlimb for the nerve repair surgery in which the 15-mm-long $\mathrm{CP}$ nerve graft $\left(\mathrm{CP}_{\mathrm{g}}\right)$ was sutured between the proximal TIB $\left(\mathrm{TIB}_{\mathrm{p}}\right)$ and distal CP $\left(\mathrm{CP}_{\mathrm{d}}\right)$ nerve stumps with silk 8-0 epineural sutures (Fig. 1A). The length of the $\mathrm{CP}_{\mathrm{d}}$ nerve stump was $\sim 15 \mathrm{~mm}$ to its entry into the TA muscle. The distal TIB $\left(\mathrm{TIB}_{\mathrm{d}}\right)$ and the proximal $\mathrm{CP}\left(\mathrm{CP}_{\mathrm{p}}\right)$ nerve stumps were sutured to nearby innervated muscles to prevent entry of regenerating axons into the $\mathrm{CP}_{\mathrm{d}}$ nerve stump and axon outgrowth from the $\mathrm{TIB}_{\mathrm{d}}$ nerve stump as previously described (Fu and Gordon, 1995a,b, 1997; You et al., 1997; Sulaiman and Gordon, 2000, 2003; Boyd and Gordon, 2003a; Gordon et al., 2003; Xu et al., 2003; Sulaiman et al., 2005).

The delayed $\mathrm{TIB}_{\mathrm{p}}-\mathrm{CP}_{\mathrm{g}}-\mathrm{CP}_{\mathrm{d}}$ repair surgeries were the same as for the immediate repair surgery except for the delay of 41-521 d between the first and second surgeries (Fig. 1). In the first surgery, the right TIB nerve was cut and the proximal nerve stump ligated to prolong TIB motoneuron axotomy (Fig. $1 B$ ) or the left distal CP nerve stump was ligated 20 $\mathrm{mm}$ from TA muscle to harvest a chronically denervated $\mathrm{CP}_{\mathrm{g}}$ nerve graft (Fig. 1C), or the left CP nerve was cut and the proximal stump ligated to prevent regeneration and thereby prolong the denervation of the CP distal nerve stump $\left(\mathrm{CP}_{\mathrm{d}}\right)$ and the TA muscle (Fig. $1 D$ ). After the nerve surgeries, the muscle layers and skin incisions were closed with 4-0 silk sutures.

Buponorphine was administered to all rats to reduce postoperative pain. The rats were allowed to recover from anesthesia under a heat lamp.

\section{Recording of TA muscle and motor unit EMG and} contractile forces

The final acute experiment was performed an average ( \pm SE) of $326 \pm$ $16 \mathrm{~d}$ after immediate or delayed $\mathrm{TIB}_{\mathrm{p}}-\mathrm{CP}_{\mathrm{g}}-\mathrm{CP}_{\mathrm{d}}$ repair surgery to ensure sufficient time for nerve regeneration through the $\mathrm{CP}$ autograft and the $\mathrm{CP}$ distal nerve stump for reinnervation of the denervated TA muscle and for the full recovery of the denervated muscle fibers from denervation atrophy (Fu and Gordon, 1995b; Sulaiman and Gordon, 2000). Identical experiments were performed on the 32 age-matched normal control animals. The body weight of the rats ranged between 250 and $650 \mathrm{~g}$.

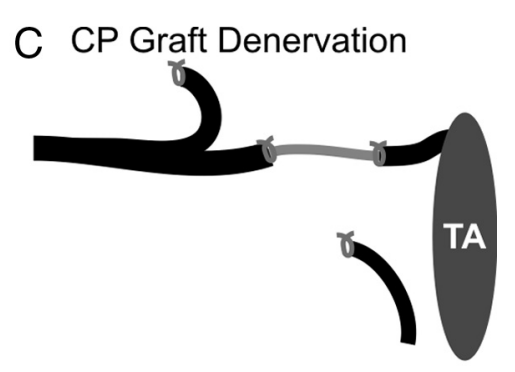

D TA Muscle Denervation

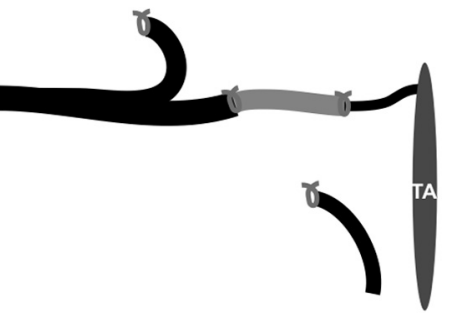

Figure 1. Surgical procedures for nerve cross-suture. The proximal stump of the cut tibial $\left(\mathrm{TIB}_{\mathrm{p}}\right)$ nerve was cross-sutured to the distal stump of the cut common peroneal $\left(\mathrm{CP}_{\mathrm{d}}\right)$ via a $15 \mathrm{~mm}$ CP nerve graft $\left(\mathrm{CP}_{\mathrm{g}}\right)$ taken from the contralateral hindlimb. The 政 and ligating the contralateral proximal and distal nerve stumps $\left(C_{p}\right.$ and $\left.C_{d}\right)$ to harvest a chronically denervated $C_{g}$ nerve graft ve to prolong denervation of both the $\left(P\right.$ distal nerve stump $\left(\mathrm{CP}_{\mathrm{d}}\right)$ and the TA muscle $(\boldsymbol{D})$.

Experimental preparation. The rats were glucose-loaded for $2 \mathrm{~d}$ before the experiments by adding glucose to the drinking water in a $5 \%$ solution. This procedure promotes glycogen synthesis in muscle fibers that, in turn, permits clear distinction of glycogen-depleted muscle fibers of isolated single motor units from nonunit muscle fibers (Tötösy de Zepetnek et al., 1992a). Rats were anesthetized by intraperitoneal administration of sodium pentobarbital $(45 \mathrm{mg} / \mathrm{kg})$ and the depth of surgical anesthesia was maintained by insertion of a venous cannula in the neck for injection of a 1:5 dilution of the anesthetic when necessary. The $5 \%$ glucose solution infusion maintained blood pressure and blood glucose levels (Tötösy de Zepetnek et al., 1992b; Fu and Gordon, 1995a, 1997).

A laminectomy was performed to expose the spinal cord from T12 to L6 for isolation of the L4 and L5 contributing ventral roots to the TA muscle in the right hindlimb (Fig. 2). The right sciatic nerve was exposed to place two fine wire electrodes on either side of the nerve for maximal stimulation. The reinnervated TA muscle was exposed and all muscles except the TA were denervated. Electromyographic (EMG) signals were recorded from the TA muscle using bipolar electrodes fixed $5 \mathrm{~mm}$ apart on a SILASTIC sheet and sewn onto the fascia of the muscle. The skin was closed around the muscle leaving the 00 silk suture attached to the distal tendon protruding at the ankle for attachment to a Grass force transducer (FT03) to record isometric force from the TA muscle. The rat was mounted rigidly to a steel table with clamps to fix the knees and ankles. The skin on the back was held stretched open with rubber bands fixed to posts on the table and a spinal pool of mineral oil was formed. The ventral roots L4 and L5 were identified and cut from the spinal cord. A heating blanket and a radiant heat maintained core temperature of $37^{\circ} \mathrm{C}$ and muscle temperature of $34^{\circ} \mathrm{C}$, monitored using a rectal probe and subcutaneous probes in the hindlimbs.

Electrophysical recordings. Force and EMG signals were amplified and digitized in millinewtons and millivolts, respectively, at appropriate sampling rates (EMG, $12.5 \mathrm{kHz}$; twitch, $1250 \mathrm{~Hz}$; tetanus, $500 \mathrm{~Hz}$ ). Stimulation of the nerve or ventral root filaments was repeated up to 30 times at $0.5-1 \mathrm{~Hz}$ to average contractile force and EMG, especially for the recordings of small motor unit contractile forces. Springs in the force transducer were adjusted for 10 and $0.05 \mathrm{~N}$ maximum force ranges for whole-muscle and motor unit recordings, respectively. An example of 
A Muscle and Motor Unit Recording

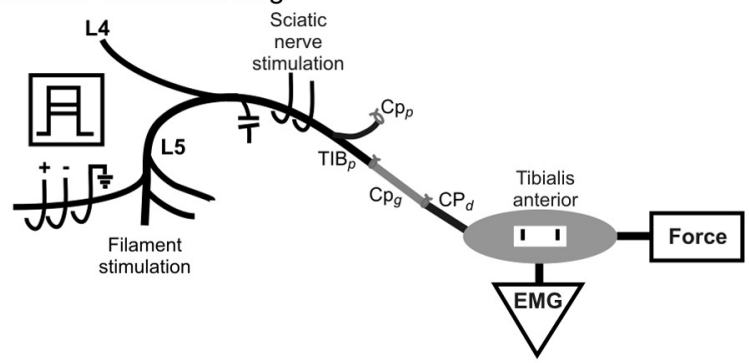

B Summated Motor Units
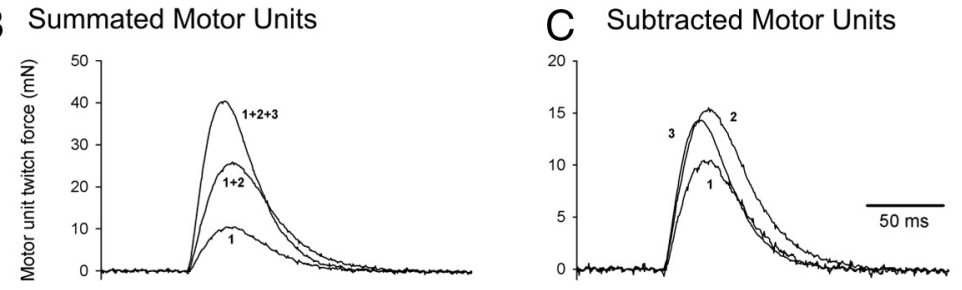

D TA Muscle

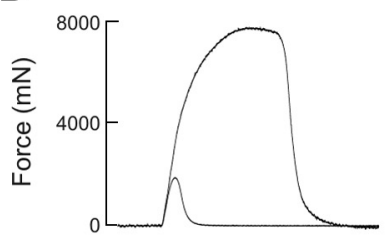

E Motor Unit Number
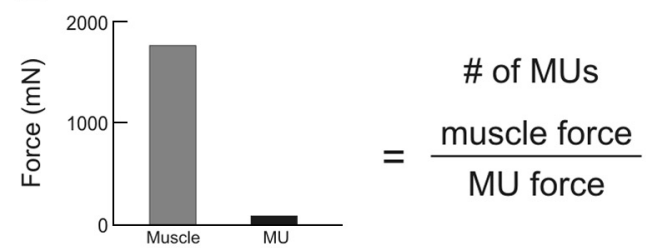

F Fatigue Test

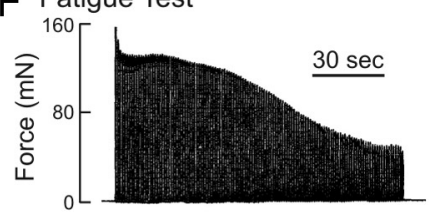

G Glycogen Depletion
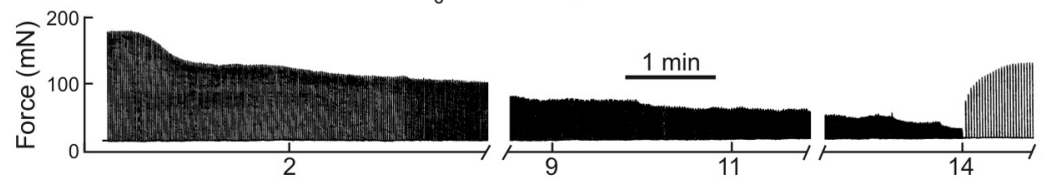

Figure 2. In vivo recording of TA muscle and motor unit forces and glycogen depletion of a single muscle unit. The sciatic nerve was stimulated to evoke isometric twitch and tetanic forces of the TA muscle $(\boldsymbol{A}, \boldsymbol{D})$ and dissected ventral root filaments in $L 4$ and $L 5$ stimulated to evoke a maximum of four all-or-none increments in twitch force $(\boldsymbol{B})$ and electromyographic signals (data not shown). The motor unit forces were obtained by subtraction (C). The number of reinnervated motor units was calculated as the ratio of the muscle and average motor unit (MU) twitch forces $(\boldsymbol{E})$. A single motor unit was isolated by being evoked by $2 \times$ threshold stimulation of a teased ventral root filament. The muscle unit twitch and maximal tetanic isometric forces were recorded; fatigue resistance was calculated from the ratio of the unfused tetanic forces at $40 \mathrm{~Hz}$ at 0 and $2 \mathrm{~min}$ of a fatigue test in which the nerve filament was stimulated with 13 pulses at $40 \mathrm{~Hz}$ at a repetition rate of $1 \mathrm{~Hz}$ for $2 \mathrm{~min}(\boldsymbol{F})$. Thereafter, the isolated single motor unit was stimulated at $100 \mathrm{~Hz}$ repeated at a rate of $1 \mathrm{~Hz}$ until the force stabilized, then at $2 \mathrm{~Hz}$, and then at $5 \mathrm{~Hz}$ until the force was reduced to $5 \%$ of the initial force $(\mathbf{G})$. The motor unit force was then allowed to recover at a stimulation rate of $0.1 \mathrm{~Hz}$. When the force had completely recovered, a second bout of fatiguing stimulation was initiated. This stimulation regime was repeated until the unit tetanic force failed to recover beyond $\sim 50 \%$ of the initial force levels.

the twitch and maximal muscle tetanic force in response to 1 and 20 pulses at $100 \mathrm{~Hz}$ is shown in Figure 2D.

The contributing L4 and L5 ventral roots were each dissected into filaments to isolate and to stimulate motor axons innervating single motor units in the TA muscle (i.e., the muscle fibers innervated by one motor axon). Teased rootlets were placed on a three electrode array (Fig. $2 \mathrm{~A}$ ) with the electrode at ground potential placed distal to the cathode and anode to reduce accidental stimulation of other nerves by volume conduction. Motor unit twitch forces were determined by recording the incremental force during graded stimulation of each nerve bundle (de Koning et al., 1989; Tam et al., 2001, 2002a,b). The technique of using incremental force to measure motor unit twitch forces (sizes) was described in detail previously and is shown in Figure 2 B. Briefly, the voltage

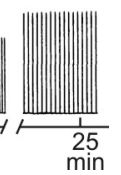

of the stimulus pulse was raised sufficiently to evoke an all-or-none unitary EMG and twitch contractile response that was recorded. Thereafter, the voltage was raised again to recruit a second all-or-none response that added to the contractile force. This procedure was repeated up to four times. If all axons have distinct thresholds, increasing the voltage of the stimulus pulse progressively recruits motor units with each new voltage level, adding the contractile force of an additional motor unit at each level. Graphical subtraction of the traces of the twitch contractions was used to estimate the contractile forces of the different motor units (i.e., subtracting the first trace from the second yields the force attributable to the second motor unit, subtracting the second trace from the third yields the twitch force of the third, and so on) (Fig. 2C). The groups of motor units were kept small, approximately three to four, to minimize the problem of alternation in which higher force levels may have different combinations of motor units being stimulated because of slight variability in stimulus thresholds (Major et al., 2007). An average of $40-80 \%$ of the $\sim 120$ motor units in the TA muscle was sampled from each muscle. The number of reinnervated motor units was determined from the ratio of the muscle twitch force to the mean motor unit force (Fig. 2E).

\section{Isolation and characterization of single motor and muscle units}

After the groups of motor units were sampled, a single axon supplying the TA muscle was isolated and the motor unit was physiologically characterized in terms of maximum tetanic force (a $200 \mathrm{~ms}$ train of pulses at $100 \mathrm{~Hz}$ ), fatigability $(40 \mathrm{~Hz}$ stimulation in 50-ms-long trains repeated every second for $2 \mathrm{~min}$ ) (Fig. $2 F$ ), and sag during an unfused tetanic contraction (800 ms train of pulses delivered at an interpulse interval at $1.25 \times$ the twitch contraction time) (Tötösy de Zepetnek et al., 1991, 1992a,b).

The isolated motor unit was subjected to repetitive muscle contraction to deplete its muscle fiber of glycogen; thereafter, the muscle was removed and stained with periodic acid-Schiff (PAS) staining to detect glycogen as described in detail previously (Tötösy de Zepetnek et al., 1991, 1992a,b). Briefly, an isolated motor unit was stimulated to deplete its glycogen content using intermittent trains of five stimulus pulses with a $10 \mathrm{~ms}$ interpulse interval $(100 \mathrm{~Hz}) \mathrm{re}-$ peated every second ( $1 \mathrm{~Hz}$ frequency). A steady decline in force was produced, and, when the decline plateaued, the train repetition rate was increased progressively from 1 to $3.3 \mathrm{~Hz}$ to continue to fatigue the motor unit muscle fibers until the unit force was reduced to $5 \%$ of the initial force. Thereafter, motor unit force was encouraged to recover by reducing the train repetition rate to $0.1 \mathrm{~Hz}$ (Fig. 2G). The fatiguing and recovery periods of stimulation were repeated until motor force failed to recover, approximately four repetitions for fatigable motor units and up to eight for fatigue-resistant motor units. This protocol ensured that the muscle unit fibers were well depleted of glycogen and allowed for unequivocal identification of the depleted muscle unit fibers. Immediately after this depletion protocol, the muscle was quickly removed, blotted, dried on filter paper for weighing, frozen in melting isopentane, and stored at $-70^{\circ} \mathrm{C}$. The muscle was 
later cut into serial sections $10 \mu \mathrm{m}$ thick and stained with PAS to identify the glycogendepleted muscle fibers (Fig. $3 A, D, G, J$ ). Sequential muscle cross-sections were also stained for myosin ATPase after acid and alkaline preincubations to determine muscle fiber type (Fig. $3 B, E, H, K$ ) (Brooke and Kaiser, 1970; Guth and Samaha, 1970). Camera lucida drawings were made from the PAS-stained muscle crosssections in which glycogen-depleted fibers were outlined within the whole-muscle cross-section (Fig. 3C, F, I,L). As described previously (Tötösy de Zepetnek et al., 1992a), such drawings were made from a number of sections taken at different proximo-distal levels along the muscle. The cross-sections yielding the largest number of muscle fibers were selected for territorial analysis (Tötösy de Zepetnek et al., 1992a; Wang and Kernell, 2000).

Using photographs or digitized images of the muscle cross-section, we counted the number of fibers in the depleted muscle unit, determined the muscle fiber areas, and the territory containing the unit fibers. The motor unit territory was defined as the area limited by lines connecting the outermost glycogen-depleted muscle fibers (Edström and Larsson, 1987).

\section{Data analysis and statistics}

Mean values are given with SEs of the mean $( \pm \mathrm{SE})$. Differences between mean values were tested using a standard Student $t$ test or ANOVA for comparisons of more than two experimental groups. Differences between distributions of unit variables were tested with the KolmogorovSmirnov test (Fisz, 1963). In all cases, statistical significance was taken at the $5 \%$ level of confidence.

\section{Results}

We determined the independent effects of prolonged motoneuron axotomy, distal nerve stump pre-degeneration, and muscle denervation on the success of axonal regeneration and muscle reinnervation. To do so, we used a cross-union graft repair method to independently vary the periods of axotomy, autologous nerve graft denervation, and tibialis anterior (TA) muscle denervation before nerve repair. A total of 122 female rats were used: 32 were unoperated controls and 90 underwent surgery in which the proximal stump of the cut tibial $\left(\mathrm{TIB}_{\mathrm{p}}\right)$ nerve was sutured to the distal stump of a cut common peroneal $\left(\mathrm{CP}_{\mathrm{d}}\right)$ nerve via a contralateral $15 \mathrm{~mm} \mathrm{CP}$ autologous nerve graft $\left(\mathrm{CP}_{\mathrm{g}}\right), \mathrm{TIB}_{\mathrm{p}}-$ $\mathrm{CP}_{\mathrm{g}}-\mathrm{CP}_{\mathrm{d}}$ repair surgery, either immediately $(n=10)$ (Fig. $\left.1 \mathrm{~A}\right)$ or after delays of $41-521 \mathrm{~d}(n=80)$. Effects of prolonged TIB motoneuron axotomy $(n=25)$ (Fig. $1 B)$, CP autologous nerve graft denervation $(n=29)$ (Fig. $1 C)$, and CP distal stump and TA muscle denervation $(n=26)$ (Fig. $1 D)$ were compared with those of immediate nerve repair in each case.

The time intervals between the $\mathrm{TIB}_{\mathrm{p}}-\mathrm{CP}_{\mathrm{g}}-\mathrm{CP}_{\mathrm{d}}$ repair surgery and the final experiment of reinnervated TA muscle and motor unit force recordings were not significantly different for the three experimental groups of chronic TIB axotomy, CP graft denerva-

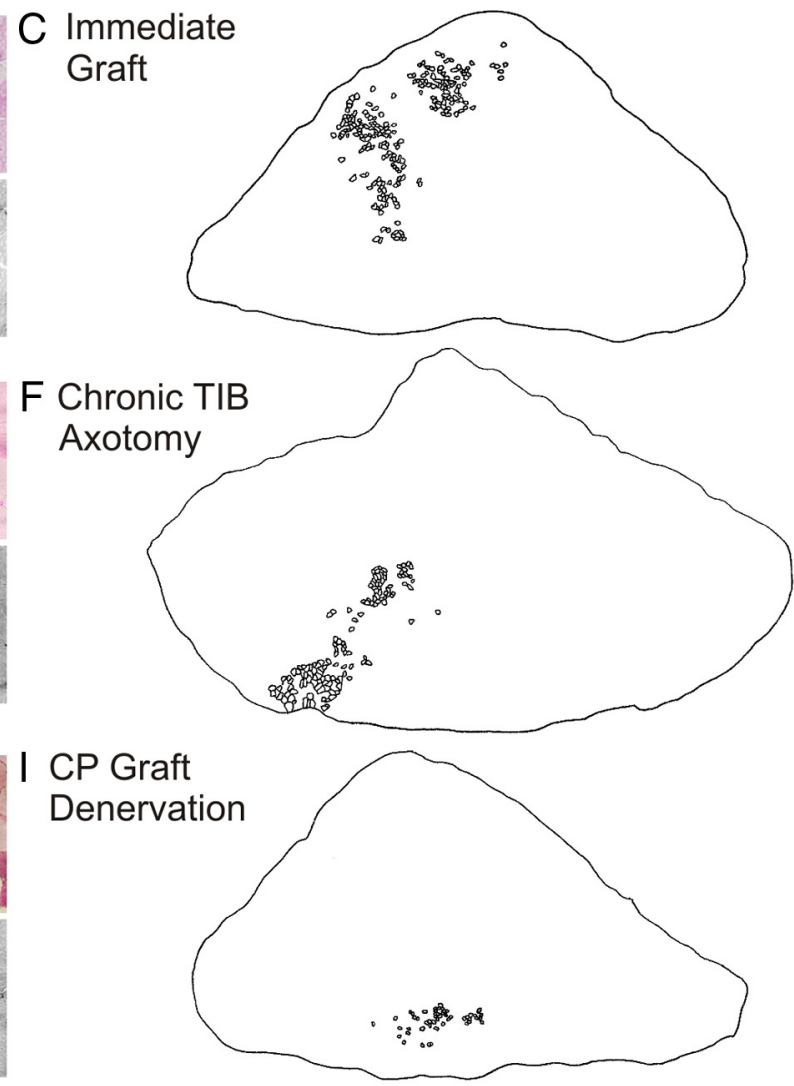

\section{TA Muscle Denervation}

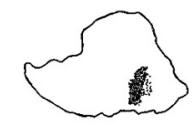

$\overline{1 \mathrm{~mm}}$

Figure 3. Comparison of muscle cross-sectional areas and muscle unit fibers in reinnervated TA muscles at least 6 months after immediate graft repair $(\boldsymbol{A}-\boldsymbol{C})$ or after a $\sim 12$ months delayed graft repair after chronic TIB nerve axotomy $(\boldsymbol{D}, \boldsymbol{E}),(P$ autograft denervation $(\mathbf{G}-\boldsymbol{I})$, or TA muscle denervation $(\boldsymbol{J}-\boldsymbol{L})$. Examples are shown of muscle fibers that are negative for the PAS reaction and clumping of muscle fibers within the outer borders of all of the muscle unit fibers of a glycogen depleted muscle unit (innervated by a single motoneuron) is shown in camera lucida drawings after immediate repair $(\boldsymbol{C})$ and after delayed nerve repair when the $C P$ motoneurons were chronically axotomized $(\boldsymbol{F})$, the CP nerve graft $(\boldsymbol{I})$, and the TA muscle $(\boldsymbol{L})$ were chronically denervated.

tion, and TA muscle denervation $(p<0.05)$. Hence, we combined the intervals for the three groups, the mean $( \pm S E)$ time interval being $326 \pm 16 \mathrm{~d}$. We had previously demonstrated full recovery of force and weight of reinnervated TA muscles within $\sim 150-180$ d under conditions in which nerve resuture or crosssuture was performed at the same level of CP nerve transection $\sim 15 \mathrm{~mm}$ from the entry of the nerve into the flexor musculature (Tötösy de Zepetnek et al., 1992a; Fu and Gordon, 1995a,b). A considerably longer period of time would be expected after $\mathrm{TIB}_{\mathrm{p}}-$ $\mathrm{CP}_{\mathrm{g}}-\mathrm{CP}_{\mathrm{d}}$ repair surgery because axons regenerate from the proximal $\mathrm{TIB}_{\mathrm{p}}$ stump through a $15 \mathrm{~mm}$ nerve graft into the distal $\mathrm{CP}_{\mathrm{d}}$ nerve stump. Furthermore, in the experimental groups in which TIB axotomy, CP graft denervation, or the TA muscle denervation were each prolonged for up to $\sim 500 \mathrm{~d}$, even longer periods of time for maximum nerve regeneration and recovery of muscle from denervation atrophy are likely. TA muscle and motor unit 

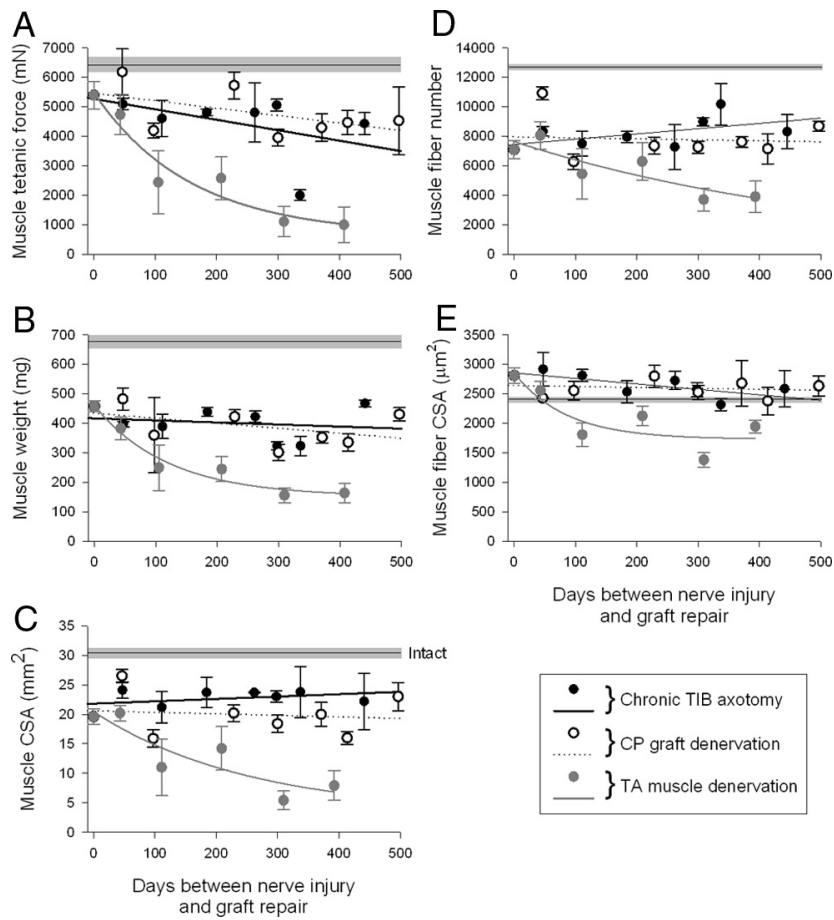

and graft repair

$$
\begin{aligned}
& \frac{\bullet}{\circ} \text { \}Chronic TIB axotomy } \\
& \text { ….. J CP graft denervation } \\
& - \text { JTA muscle denervation }
\end{aligned}
$$

and graft repair

Figure 4. Effects of chronic axotomy, nerve graft denervation, and prolonged distal nerve stump and muscle denervation on muscle tetanic force $(\boldsymbol{A})$, wet weight $(\boldsymbol{B}), \mathrm{CSA}(\boldsymbol{C})$, and muscle fiber number $(\boldsymbol{D})$, and $C S A(\boldsymbol{E})$ after $\mathrm{TIB}_{\mathrm{p}}-\mathrm{CP}_{\mathrm{g}}-\mathrm{CP}_{\mathrm{d}}$ nerve repair surgery and regeneration. Nerve repair was performed via an autologous $15 \mathrm{~mm} C P$ nerve graft between the TIB proximal nerve stump and the distal CP nerve stump that required chronically axotomized TIB motoneurons to regenerate axons across two suture lines to reinnervate the distal nerve stump and grow to reinnervate the denervated TA muscle, $T I B_{p}-C P_{g}-C P_{d}$ repair surgery. The mean values ( $\pm S E$ ) of each parameter in the reinnervated TA muscles immediately after repair surgery differed significantly from the mean ( $\pm \mathrm{SE}$ ) values of intact TA muscles in unoperated rats (shown by straight black line and gray bar). (hanges in parameters as a function of the days between either TIB nerve axotomy $(\bigcirc)$, CP nerve graft denervation $(\bigcirc)$, or TA muscle denervation $(O)$ and nerve repair are fitted by regression lines. In both cases of TIB nerve axotomy and CP nerve graft denervation, the lines did not differ significantly from zero ( $p>0.05)$, indicating no change as a function of chronic axotomy or chronic $C P$ graft denervation before nerve repair. The slopes of the regression lines fitted to the data of chronic axotomy and chronic $C P$ graft denervation were $-3.54 \pm 2.48$ and $-2.5 \pm 1.51(\boldsymbol{A}),-0.07 \pm 0.15$ and $-0.17 \pm 0.13(\boldsymbol{B}), 0.004 \pm 0.004$ and $-0.003 \pm 0.088(\boldsymbol{C}), 3.61 \pm 2.30$ and $-0.65 \pm 3.19(\boldsymbol{D})$, and $-0.93 \pm 0.36$ and $-0.16 \pm 0.35(\boldsymbol{E})$. In contrast, all the same parameters declined exponentially as a function of duration of $C P$ distal nerve stump and TA muscle denervation to significantly lower values $(p<$ 0.05). The time constants for the exponential declines were $156(\boldsymbol{A}), 122(\boldsymbol{B}), 256(\boldsymbol{C}), 556(\boldsymbol{D})$, and $86 \mathrm{~d}(\boldsymbol{E})$

forces were compared with those of muscles from unoperated age-matched controls (CON: $n=32$; body weight, $291 \pm 70 \mathrm{~g}$ ) because the contralateral left TA muscles were denervated by preparation of the CP graft.

\section{Immediate nerve repair via a nerve graft does not lead to full recovery}

Before evaluating delayed nerve sutures, we immediately repaired nerves after nerve transection and evaluated the regenerative success after the $\mathrm{TIB}_{\mathrm{p}}-\mathrm{CP}_{\mathrm{g}}-\mathrm{CP}_{\mathrm{d}}$ repair surgery. All the reinnervated muscle parameters of tetanic force, weight, cross-sectional area (CSA), and fiber number, were significantly less than normal after nerve regeneration across the two suture lines after the $\mathrm{TIB}_{\mathrm{p}}-$ $\mathrm{CP}_{\mathrm{g}}-\mathrm{CP}_{\mathrm{d}}$ repair surgery (Fig. $4 A-D$ ). Muscle fiber CSA was significantly greater after the surgery (Fig. $4 E$ ). The number of muscle fibers reinnervated by each motoneuron, the innervation ratio, was not changed (Fig. $5 H$ ).
A
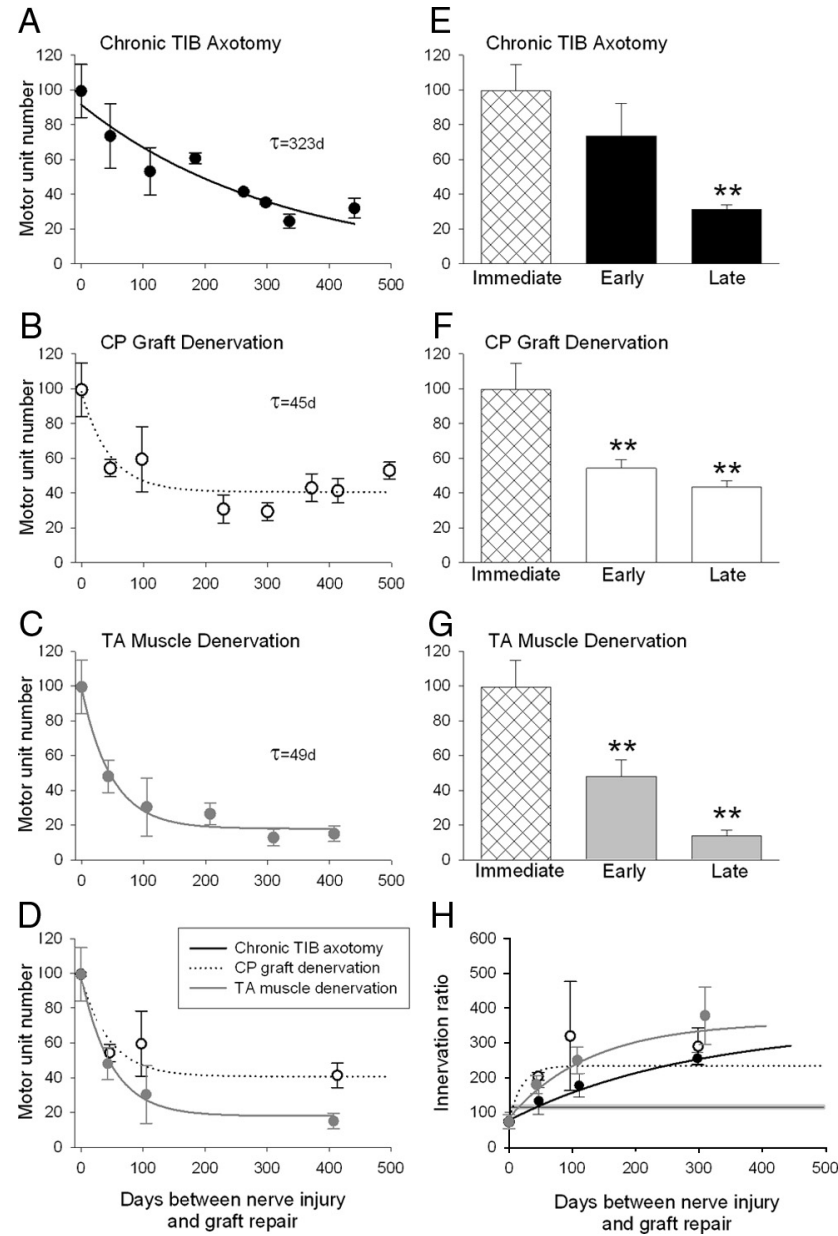

Figure 5. Comparison of (1) the exponential decline in numbers of motoneurons that reinnervated TA muscle (motor unit number), (2) mean motor unit numbers after immediate, early, and late periods of chronic axotomy $(\boldsymbol{O})(\boldsymbol{A}, \boldsymbol{E}), \mathrm{CP}$ graft denervation $(\bigcirc)(\boldsymbol{B}, \boldsymbol{D}, \boldsymbol{F})$, and nerve stump and muscle denervation $(\mathbf{O})(\boldsymbol{C}, \boldsymbol{D}, \boldsymbol{G})$, and (3) exponential increase in the numbers of muscle fibers reinnervated by each motoneuron, the innervations ratio $(\boldsymbol{H})$. The progressive decline in regenerative success for all three experimental conditions was fitted by exponential regression lines. The progressive decline after prolonged axotomy $(\boldsymbol{A})$ was slow (time constant of $323 \mathrm{~d}$ ) relative to the declines after chronic $(P$ graft $(\boldsymbol{B})$ and TA muscle denervation $(\boldsymbol{C})$ that were both rapid, the time constants of the exponential decline being the same ( 49 and $45 \mathrm{~d}$ ). The smaller asymptotic value of 19 motor units after chronic TA muscle denervation compared with the asymptotic values of 42 motor units after chronic $(P$ graft denervation $(\boldsymbol{D})$ argues that the chronic muscle denervation is an important contributing factor, in addition to chronic denervation of Schwann cells in reducing the success of delayed nerve repair after injury.

Prolonged axotomy: decline in regenerative capacity relative to immediate nerve repair is compensated for by motor unit enlargement

Axotomy of the TIB motoneurons was prolonged for up to $521 \mathrm{~d}$ by suturing the proximal TIB nerve stump to innervated muscle in the right hindlimb. The stump was then freed by cutting (a refreshment injury) and the proximal TIB nerve stump was crosssutured to a freshly cut CP distal nerve stump via a $15 \mathrm{~mm}$ freshly prepared CP nerve autograft from the contralateral hindlimbchronic TIB axotomy with a fresh graft and freshly denervated CP nerve stump and TA muscle (Fig. $1 B$ ). The recordings of reinnervated TA isometric contractile forces and the muscle weights $326 \pm 16 \mathrm{~d}$ after chronic TIB axotomy and $\mathrm{TIB}_{\mathrm{p}}-\mathrm{CP}_{\mathrm{g}}-\mathrm{CP}_{\mathrm{d}}$ repair surgery demonstrated that the muscles were equally well reinnervated after chronic TIB axotomy as after immediate nerve repair regardless of the duration of chronic axotomy (Fig. $4 A, B$ ). The 
negative slope of the regression line of tetanic force and duration of chronic TIB axotomy $(-3.5 \pm 2.5)$ was not significantly different from zero (Fig. 4A). CSAs of the muscles, measured from the widest middle portion of the muscle to include both deep and superficial areas, also recovered completely compared with immediate nerve repair (Fig. 4C). The muscle CSA included the same number of muscle fibers that had fully recovered their CSAs (Fig. 4D,E). The slopes of the regression lines fitted to the plots of muscle CSA, and muscle fiber number and CSA, were not significantly different from zero (Fig. 4C-E).

We calculated the number of motoneurons reinnervating TA muscles after immediate and chronic TIB axotomy to evaluate whether the apparent full recovery of the reinnervated muscles after chronic axotomy relative to immediate nerve repair (Fig. 5) masked incomplete reinnervation of the freshly denervated muscles by the chronically axotomized motoneurons. This would occur if fewer nerves regenerated and each of these axons supplied more muscle fibers than normal to increase the innervation ratio. Thereby the increased contractile force of the reinnervated motor units may be sufficient to sustain whole muscle force and weight. This was demonstrated previously after chronic TIB axotomy and $\mathrm{TIB}_{\mathrm{p}}-\mathrm{CP}_{\mathrm{d}}$ cross-suture without the intervening $\mathrm{CP}$ nerve graft (Fu and Gordon, 1995a). Indeed, we found that the mean $( \pm S E$ ) number of reinnervated motor units in the TA muscles did decline, falling exponentially from $99( \pm 15)$ after immediate $\mathrm{TIB}_{\mathrm{p}}-\mathrm{CP}_{\mathrm{g}}-\mathrm{CP}_{\mathrm{d}}$ repair surgery to $35( \pm 1)$ after chronic TIB axotomy with a time constant $(\tau)$ of $323 \mathrm{~d}$ (Fig. $5 A$ ). The initial decline within $50 \mathrm{~d}$ was not significant, but the decline thereafter was significant (Fig. $5 E$ ). The $\sim 66 \%$ decline in number of motor units agrees well with our previous finding that prolonged axotomy reduces the number of reinnervated motor units to $\sim 33 \%$ after delayed $\mathrm{TIB}_{\mathrm{p}}-\mathrm{CP}_{\mathrm{d}}$ repair surgery (Fu and Gordon, 1995a).

The size of the reinnnervated motor units increased with prolonged TIB axotomy as measured by innervation ratios and motor unit forces (Figs. $5 H, 6 A-D$ ). As shown in Figure $5 H$ in which only three representative mean $( \pm S E)$ values are included for clarity, the innervation ratios increased reciprocally with the decline in the number of reinnervated motor units (Fig. 5A). Increased motor unit force was evident by the rightward shift of the frequency distributions of the motor unit tetanic forces from immediate to early $(<50 \mathrm{~d})$ and late $(>300$ d) periods of chronic TIB axotomy before surgical repair (Fig. $6 A-C)$. Consistent with the slow $\tau$ of decline in motor unit numbers (Fig. 5A), mean motor unit tetanic forces increased relatively slowly to reach significantly higher levels after long periods of chronic axotomy $(p<0.05)$ (Fig $6 A-C)$. When the force data were plotted as cumulative force distributions, the rightward shifts of the distributions were significant within $50 \mathrm{~d}$ (Kolmogorov-Smirnov, $p<0.05$ ) (Fig. 6D). The progressive shifts of the tetanic forces to values of $\sim 2.5$ times the forces measured after immediate $\mathrm{TIB}_{\mathrm{p}}-\mathrm{CP}_{\mathrm{g}}-\mathrm{CP}_{\mathrm{d}}$ repair surgery reflected similar elevations in innervation ratios (Fig. $5 \mathrm{H}$ ) as the numbers of chronically axotomized TIB motoneurons that reinnervated TA muscles declined (Fig. 5A).

In summary, chronic axotomy resulted in a significant decline in the capacity of freshly axotomized TIB motoneurons to regenerate and reinnervate freshly denervated TA muscles. The regenerated axons form maximally enlarged motor units to include all denervated muscle fibers, such that muscle force, weight, and CSA are sustained and reinnervated muscle fibers number and CSA are the same as after immediate nerve repair. 


\section{Prolonged nerve graft denervation rapidly reduces regenerative success}

Denervation of the contralateral CP nerve graft was prolonged for up to $500 \mathrm{~d}$ by cutting the contralateral CP nerve in the thigh of the left hindlimb and suturing the proximal nerve stump to innervated muscle. Thereafter, the denervated nerve stump was freed from the ligature and a $15-\mathrm{mm}$-long CP nerve graft was removed for transplantation into the right hindlimb. It was then placed to bridge between a freshly cut TIB proximal nerve stump and a freshly cut CP distal nerve stump-a chronically denervated CP nerve graft between a freshly axotomized TIB nerve and freshly denervated CP nerve stump and TA muscle-CP graft denervation (Fig. 1C).

As was the case after chronic axotomy of the TIB motoneurons, the reinnervated TA muscles fully recovered the same tetanic contractile force, weight, and CSA after chronic CP nerve graft denervation as the reinnervated muscles after immediate $\mathrm{TIB}_{\mathrm{p}}-\mathrm{CP}_{\mathrm{g}}-\mathrm{CP}_{\mathrm{d}}$ repair surgery (Fig. $4 A-C$ ). The slopes of the fitted regression lines of the parameters plotted as a function of the duration of chronic denervation of the nerve graft were not significantly different from zero (Fig. $4 A-C$ ). There was also no significant decline in the number or size (CSA) of muscle fibers (Fig. $4 D, E$ ). These data demonstrate that the muscles had become well reinnervated with full recovery of contractile function and size when freshly axotomized TIB motoneurons regenerated their axons through a chronically denervated CP nerve graft.

This full recovery of muscle parameters concealed a significant decline in the number of TIB motoneurons that regenerated their axons through the chronically denervated CP nerve graft to reinnervate the freshly denervated TA muscle (Fig. $5 B$ ). The rapid decline with a time constant of $45 \mathrm{~d}$ for chronic CP graft denervation contrasted with the slow decline of regeneration $(\tau$ of 323 d) by chronically axotomized TIB motoneurons (Fig. 5A). The asymptotic mean $( \pm \mathrm{SE})$ number of $41( \pm 10)$ motor units after chronic CP graft denervation represents a $\sim 60 \%$ decline in motor unit numbers that compares closely with $\sim 66 \%$ decline in numbers after chronic TIB axotomy. The rapid decline to asymptotic levels was also evident from the same mean number of reinnervated motor units after prolonged CP graft denervation at 50 and $>300 \mathrm{~d}$ (Fig. $5 F$ ). The reinnervated motor units increased in size as measured by significant increases in motor unit forces (Fig. $6 E-G$ ) and in innervation ratios (Fig. $5 H$ ). There was a significant shift in frequency and cumulative histograms to the right to larger contractile forces for prolonged CP graft denervation of $<50 \mathrm{~d}$ that did not shift further when the CP graft denervation was prolonged for $>300 \mathrm{~d}$ (Fig. $6 E-G$ ). The $\sim 2$ - to 2.5 -fold increase in motor unit size within $50 \mathrm{~d}$ compensated fully for the rapid reduction in the number of axons that regenerated through the chronically denervated nerve graft.

In summary, chronic denervation of the contralateral $\mathrm{CP}$ nerve graft resulted in a significant decline in the capacity of freshly axotomized motoneurons to regenerate and reinnervate freshly denervated TA muscles. Our current data demonstrate the strong inhibitory effect of chronically denervated Schwann cells in the denervated nerve graft. These data support our original argument that chronic Schwann cell denervation, not the chronic denervation of targets, accounted for the progressive failure of axon regeneration with time and distance. Indeed, these findings indicate that reduced capacity of the denervated Schwann cells to support axonal regeneration is not directly related to the reduced neurotrophic effect of the denervated targets, as previously indicated (Bain et al., 2001, 2008; Zhao et al., 2004; Elsohemy et al., 2009).

\section{Prolonged distal nerve stump and muscle denervation have the most deleterious effect on regenerative success}

In contrast to the fully recovered muscle contractile force, weight, and size and to the restored muscle fiber number and size after chronic motoneuron axotomy or nerve graft denervation, prolonged denervation of the $\mathrm{CP}$ distal nerve stump and the flexor muscle group before $\mathrm{TIB}_{\mathrm{p}}-\mathrm{CP}_{\mathrm{g}}-\mathrm{CP}_{\mathrm{d}}$ repair surgery did have a significant negative effect on all these muscle parameters (Fig. 4). Muscle contractile force, weight, and size (CSA) declined progressively as a function of the duration of chronic denervation before surgical repair (Fig. $4 A-C$ ). In each case, the exponential fall reduced the muscle functional properties to a lower plateau with $\tau$ values of 156, 122, and $256 \mathrm{~d}$ for muscle tetanic force, weight, and CSA, respectively (Fig. $4 A-C$ ). The declines were accounted for, in part, by a fall in the numbers of reinnervated motor units from $99 \pm 15$ to $13+5$ (Fig. $5 C$ ). The latter decline was only partially compensated for by the maximal threefold increase in innervation ratio (Fig. $5 \mathrm{H}$ ). As a result, the number of reinnervated muscle fibers declined (Fig. $5 H$ ). A second contributing factor to the reduced muscle force, weight, and size after chronic denervation was the progressive failure of the reinnervated muscle fibers to recover their former size after chronic TA muscle denervation (Fig. $4 E$ ), a phenomenon noted previously (Fu and Gordon, 1995b). After short periods of denervation of $<50 \mathrm{~d}$ when the reinnervated muscles fibers did recover their size fully (Fig. $4 E$ ), motor unit forces were increased significantly (Fig. $6 H$ ) as the number of motor units declined (Fig. $5 C$ ). For longer periods, the reduced muscle fiber CSAs (Fig. $4 E$ ) led to an underestimation of the motor unit size as measured by motor unit forces (Fig. 6I, J). The progressive increase in motor unit size was clear from the increased innervations ratios, however (Fig. 5H).

The exponential decline in motor unit numbers after chronic distal CP nerve and TA muscle denervation was more rapid and more severe than after either chronic axotomy or chronic nerve graft denervation (Fig. 5). Interestingly, the time course and the extent of the early decline to $50 \%$ was the same as after chronic nerve graft denervation but motor unit numbers continued to decline to even lower levels of $\sim 10 \%$ when the distal CP nerve stump and the TA muscle were chronically denervated for $>50 \mathrm{~d}$ (Fig. 5D). The exponential decline to $\sim 10 \%$ corresponded closely with the decline in number of reinnervated motor units and number of regenerated axons after cross-suture of the TIB and chronically denervated CP distal nerve stumps (Fu and Gordon, 1995b; Sulaiman and Gordon, 2000). However, the previous studies could not delineate the effects of chronic nerve sheath denervation from the denervation of the muscle itself, the chronically denervated nerve stump and the muscle being in continuity with each other in the present and the past studies. The direct comparison of the early fall in numbers of reinnervated motor units after chronic denervation of the CP nerve graft alone with the fall after chronic denervation of the nerve stump and the muscle in the present study show that the rapid early decline is accounted for by the Schwann cell denervation and the later decline by the connection with the chronically denervated muscle (Fig. 5D).

The dramatic effect of chronic muscle denervation in reducing the capacity of the muscle to recover is illustrated in Figure 3. Camera lucida drawings of typical muscle cross-sections are shown after immediate nerve repair and after delayed nerve repair surgery of chronically axotomized TIB motoneurons, of a chronically denervated CP autograft, and of chronically denervated $\mathrm{CP}$ distal nerve stump and TA muscle. The size of the 
reinnervated muscles after chronic axotomy and graft denervation was the same as after immediate nerve repair (Fig. 3, compare $F, I$, with $C$ ). In contrast, the size of the muscles was obviously smaller after prolonged chronic denervation (Fig. $3 L$ ). Not only were there fewer muscle fibers (Fig. $3 F$ ) but the size of the fibers was visibly reduced (Fig. $3 J, K$ ) compared with those after immediate, chronic axotomy or graft denervation (Fig. $3 A, B, D, E, G, H)$.

The muscle fibers stained for PAS are white after glycogen depletion by repetitive stimulation of an isolated motor axon (see Materials and Methods) (Fig. 2). Thereby the grouped distribution of the muscle unit fibers, typical of reinnervated muscles, was seen whether or not $\mathrm{TIB}_{\mathrm{p}}-\mathrm{CP}_{\mathrm{g}}-\mathrm{CP}_{\mathrm{d}}$ repair surgery was immediate or delayed to prolong motoneuron axotomy, autograft denervation, or muscle denervation (Fig. $3 A, C, D, F, G, I, J, L)$. All the muscle fibers of the units displayed are type IIB with negative staining with acid ATPase (Fig. $3 B, E, H, K$ ).

In summary, chronic denervation of Schwann cells in the distal nerve stump and the chronic denervation of the muscle of reinnervation together inhibit the capacity of even freshly axotomized motoneurons to regenerate their axons and to reinnervate muscles. However, it is not simply that the chronically denervated muscles are replaced by fat (as is commonly believed) that accounts for the very poor axon regeneration and muscle reinnervation. Rather, it appears that, indeed as indicated by the findings of Bain and coworkers (Bain et al., 2001, 2008; Zhao et al., 2004; Elsohemy et al., 2009), the chronically denervated muscle has a negative retrograde effect on the capacity of motoneurons to regenerate their axons, In addition, chronically denervated muscle fibers fail to fully recover from denervation atrophy despite innervation. This is discussed in detail in Discussion.

\section{Discussion}

We used a novel rat model of nerve injury and quantitative outcome measures of regenerative success to systematically and individually prolong axotomy of motoneurons, Schwann cell (SC) and muscle denervation before repair surgery. Our findings demonstrate that chronic denervation of the distal nerve stump in and of itself is a determining factor limiting functional recovery: numbers of neurons regenerating their axons declined within $50 \mathrm{~d}$ of chronic denervation. The $60 \%$ decline was the same whether or not the chronically denervated distal nerve stump maintained continuity with denervated muscle. The number of motoneurons regenerating axons fell to $\sim 15 \%$ of the number after immediate nerve repair only when axons grew through a freshly denervated nerve graft into a chronically denervated distal stump that was connected to denervated muscle. This comparison of the growth support of chronically denervated SCs alone and in continuity with denervated muscle demonstrates the crucial contribution of the SC atrophic changes to progressive regenerative failure as well as providing partial support for the conclusion that chronic muscle denervation reduces the regenerating capacity of neurons after long delays (Michalski et al., 2008).

\section{Prolonged axotomy}

The reduction of $67 \%$ in numbers of chronically axotomized motoneurons regenerating axons through two suture lines to reinnervate freshly denervated muscle corresponded very closely with the reduction in reinnervated motor unit numbers we reported after regeneration through one suture site (Fu and Gordon, 1995a). Concomitant increase in motor unit size fully compensated for reduced numbers of motor units (Fig. 5), their enlargement being sufficient to reinnervate all denervated muscle fibers. Consequently, reinnervated muscles developed as much contractile force, were as heavy, and had the same CSAs as when $\mathrm{TIB}_{\mathrm{p}}-\mathrm{CP}_{\mathrm{g}}-\mathrm{CP}_{\mathrm{d}}$ repair surgery was performed immediately (Fig. 4). Additionally, muscle fiber size and number were the same.

Ligation of the proximal nerve stump to prevent axon regeneration and reconnection with target muscle was used to model chronic axotomy (Fig. 2). The frustrated axon regeneration is a reasonable model of prolonged axotomy because the reduced capacity of chronically axotomized motoneurons to regenerate their axons was the same after frustrating axon growth by nerve ligation as that after allowing axon growth through a cutaneous sensory nerve graft that prevented muscle reinnervation (Furey et al., 2007). Moreover, no neuron death ensued after chronic axotomy of the motoneurons supplying hindlimb muscles regardless of how often the neurons were subjected to crush injury (Gordon et al., 1991; Xu et al., 2010).

The molecular response of axotomized neurons with upregulation of actin, tubulin, GAP-43, and CAP-23, the expression of the neonatal isoform, $\alpha$-tubulin, and the downregulation of neurofilament protein (Tetzlaff et al., 1988; Miller et al., 1989; Jacob and McQuarrie, 1996; Fu and Gordon, 1997; Bomze et al., 2001; Woolf, 2001; Mason et al., 2002) has been interpreted as evidence of a molecular switch from a transmitting to a growth mode, the genes being referred to as growth-associated genes (GAGs) (Gordon, 1983; Miller et al., 1989; Fu and Gordon, 1997). GAG expression is relatively short-lived, however, declining from a peak at $7 \mathrm{~d}$ to baseline levels within 6 months (You et al., 1997; McPhail et al., 2004). The decline corresponds with the decline in regenerative capacity of chronically axotomized motoneurons, although $\sim 30 \%$ of the neurons do sustain regeneration in the permissive environment of a freshly denervated nerve graft or distal stump. The increased GAG expression after the refreshment injury of the chronically axotomized motoneurons for the repair surgery is even more transient (You et al., 1997). The role in axon growth of $>240$ genes selectively expressed after nerve injury (Costigan et al., 2002; Befort et al., 2003; Seijffers et al., 2006) as well as the time course of their expression remain to be determined.

Motoneuronal upregulation of neurotrophic factors including brain- and glial cell-derived neurotrophic factors (BDNF and GDNF) and neurotrophin 4/5 occurs within $7 \mathrm{~d}$ of injury and progressively declines thereafter (Boyd and Gordon, 2003a). This decline is also likely a factor in reduced regenerative capacity with chronic axotomy. Indeed, exogenous BDNF and GDNF effectively restore regenerative capacity of chronically axotomized motoneurons without affecting the capacity after immediate axotomy (Boyd and Gordon, 2001, 2002, 2003b).

\section{Prolonged Schwann cell denervation}

The numbers of freshly axotomized TIB motoneurons that regenerated axons through a chronically denervated nerve autograft declined rapidly as a function of duration of denervation, the time constant being $45 \mathrm{~d}$ to fall to $\sim 40 \%$ of normal (Fig. $5 B, D)$. The time course demonstrates that the permissive growth environment of such autografts is transient even when grafts are short. The use of any conduit requires that regenerating axons traverse two suture sites. Denervated SCs normally migrate across these sites to assemble the laminin substrate on which regenerating axons sprout and grow. However, laminin bundles at the repair site are disorganized until $\sim 5 \mathrm{~d}$ when SCs begin to infiltrate the site. Thereafter, SCs and collagen align in organized longitudinal bands of Bungner to support the regenerating axons 
that sprout from the proximal nerve stump (Ramon y Cajal, 1928; Witzel et al., 2005) and provide visual evidence for the slow and progressive "staggered outgrowth" of regenerating axons across a suture line; all axons cross one suture line within $28 \mathrm{~d}$ (Al-Majed et al., 2000; Brushart et al., 2002). It follows that crossing of all regenerating axons into, through, and out of a $15-\mathrm{mm}-$ long nerve autograft requires $\sim 10$ weeks even after immediate nerve repair including the regeneration through the graft at a regeneration rate of $3 \mathrm{~mm} / \mathrm{d}$.

Many GAGs are upregulated in denervated SCs as they proliferate and switch from a myelinating to a growth-supportive phenotype. These include neurotrophic factors, nerve growth factor, BDNF, GDNF, and pleotrophin, their receptors, as well as neuregulin and their receptors (You et al., 1997; Höke et al., 2002; Mi et al., 2007). The genes undergo progressive decline in expression with chronic SC denervation (Boyd and Gordon, 2003a; Sulaiman et al., 2011). This decline and progressive shift of denervated SCs to a dormant state likely impacts SC migration across suture lines and their capacity to support axonal outgrowth even from a freshly cut proximal nerve stump into a freshly denervated recipient distal nerve stump. Freshly axotomized motoneurons normally derive sufficient neurotrophic support from denervated SCs, but under conditions of chronic SC denervation, the neuronal sources of the neurotrophic factors are likely inadequate to support axon regeneration without exogenous sources. Likewise, as discussed above, exogenous sources of growth factors are required by chronically axotomized neurons to sustain axon regeneration (Gordon, 2009).

Despite chronic SC denervation in the autograft, $\sim 40 \%$ of the motoneurons regenerated axons. This likely reflects the ability of freshly denervated SCs from both proximal and distal nerve stumps to which the autograft is attached, to support axon regeneration. Axons may release sufficient SC mitogens including neuregulin and CGRP (calcitonin gene-related peptide), to support some proliferative capacity of the SCs in the graft despite evidence of reduced expression of erb2 and erb3 receptors for neuregulin (Li et al., 1997; Terenghi et al., 1998; Sulaiman and Gordon, 2003).

\section{Denervation of the distal nerve stump and target organs}

Our data confirm previous findings that chronic denervation of distal CP nerve stump and of TA muscle reduces the number of regenerating motoneurons to $\sim 10 \%$ after immediate nerve repair (Fu and Gordon, 1995b). Counts of backlabeled motoneurons that regenerated their axons support the conclusion that chronic SC denervation accounts for the poor axon regeneration (Fu and Gordon, 1995b; Sulaiman and Gordon, 2000, 2009; Sulaiman et al., 2002, 2005). However, our current findings that chronic nerve autograft denervation reduced regeneration to $40 \%$ after delayed repair but denervation of $\mathrm{CP}$ nerve stump and TA muscle reduced regeneration to $\sim 10 \%$ (Fig. 5) demonstrate the negative impact of chronic muscle denervation on axon regeneration (Bain et al., 2001; Veltri et al., 2005). Exhaustion of trophic factors from the denervated muscle is likely a contributing factor, although additional investigation is warranted.

Failure of reinnervated muscle fibers to fully recover their former size is an additional factor limiting motor recovery. Satellite cells may be reduced in number, ability to replenish muscle nuclei, and/or proliferative capacity (Anzil and Wernig, 1989). A strength of the current study is our assurance of the free movement of experimental rats by specifically denervating only the muscles of interest. This is important because muscle fiber loss may be exacerbated by immobility that frequently accompanies muscle denervation. Immobilized limbs carry risk of ischemia, stasis, and edema, all of which can adversely affect muscle nutrition and their subsequent recovery (Sunderland, 1978; Savolainen et al., 1988).

\section{Conclusions}

Replacement of denervated muscle by fat is not inevitable as previously supposed. If factors that include reduced blood supply are taken into account, the ability of regenerating axons to reinnervate denervated muscle fibers and, in turn, to form maximally enlarged muscle units provides strong evidence that chronic muscle denervation is not the prime factor that accounts for poor functional recovery after proximal nerve injuries. Functional recovery is limited primarily by the progressive fall in regenerative capacity of axotomized neurons and denervated SCs with time and distance.

\section{References}

Al-Majed AA, Neumann CM, Brushart TM, Gordon T (2000) Brief electrical stimulation promotes the speed and accuracy of motor axonal regeneration. J Neurosci 20:2602-2608.

Anzil AP, Wernig A (1989) Muscle fibre loss and reinnervation after longterm denervation. J Neurocytol 18:833-845.

Bain JR, Veltri KL, Chamberlain D, Fahnestock M (2001) Improved functional recovery of denervated skeletal muscle after temporary sensory nerve innervation. Neuroscience 103:503-510.

Bain JR, Hason Y, Veltri K, Fahnestock M, Quartly C (2008) Clinical application of sensory protection of denervated muscle. J Neurosurg 109:955-961.

Befort K, Karchewski L, Lanoue C, Woolf CJ (2003) Selective up-regulation of the growth arrest DNA damage-inducible gene Gadd45 alpha in sensory and motor neurons after peripheral nerve injury. Eur J Neurosci 18:911-922.

Bomze HM, Bulsara KR, Iskandar BJ, Caroni P, Skene JH (2001) Spinal axon regeneration evoked by replacing two growth cone proteins in adult neurons. Nat Neurosci 4:38-43.

Boyd JG, Gordon T (2001) The neurotrophin receptors, trkB and p75, differentially regulate motor axonal regeneration. J Neurobiol 49:314-325.

Boyd JG, Gordon T (2002) A dose-dependent facilitation and inhibition of peripheral nerve regeneration by brain-derived neurotrophic factor. Eur J Neurosci 15:613-626.

Boyd JG, Gordon T (2003a) Neurotrophic factors and their receptors in axonal regeneration and functional recovery after peripheral nerve injury. Mol Neurobiol 27:277-324.

Boyd JG, Gordon T (2003b) Glial cell line-derived neurotrophic factor and brain-derived neurotrophic factor sustain the axonal regeneration of chronically axotomized motoneurons in vivo. Exp Neurol 183:610-619.

Brooke MH, Kaiser KK (1970) Muscle fiber types: how many and what kind? Arch Neurol 23:369-379.

Brown MC, Ironton R (1978) Sprouting and regression of neuromuscular synapses in partially denervated mammalian muscles. J Physiol 278:325-348.

Brushart TM, Hoffman PN, Royall RM, Murinson BB, Witzel C, Gordon T (2002) Electrical stimulation promotes motoneuron regeneration without increasing its speed or conditioning the neuron. J Neurosci 22:6631-6638.

Costigan M, Befort K, Karchewski L, Griffin RS, D'Urso D, Allchorne A, Sitarski J, Mannion JW, Pratt RE, Woolf CJ (2002) Replicate highdensity rat genome oligonucleotide microarrays reveal hundreds of regulated genes in the dorsal root ganglion after peripheral nerve injury. BMC Neurosci 3:16.

de Koning P, Verhaagen J, Sloot W, Jennekens FG, Gispen WH (1989) Org. 2766 stimulates collateral sprouting in the soleus muscle of the rat following partial denervation. Muscle Nerve 12:353-359.

Edström L, Larsson L (1987) Effects of age on contractile and enzymehistochemical properties of fast- and slow-twitch single motor units in the rat. J Physiol 392:129-145.

Elsohemy A, Butler R, Bain JR, Fahnestock M (2009) Sensory protection of rat muscle spindles following peripheral nerve injury and reinnervation. Plast Reconstr Surg 124:1860-1868. 
Fisz M (1963) Probability theory and mathematical statistics. New York: Wiley.

Fu SY, Gordon T (1995a) Contributing factors to poor functional recovery after delayed nerve repair: prolonged axotomy. J Neurosci 15:3876-3885.

Fu SY, Gordon T (1995b) Contributing factors to poor functional recovery after delayed nerve repair: prolonged denervation. J Neurosci 15:3886-3895.

Fu SY, Gordon T (1997) The cellular and molecular basis of peripheral nerve regeneration. Mol Neurobiol 14:67-116.

Furey MJ, Midha R, Xu QG, Belkas J, Gordon T (2007) Prolonged target deprivation reduces the capacity of injured motoneurons to regenerate. Neurosurgery 60:723-732; discussion 732-733.

Gordon T (1983) Dependence of peripheral nerves on their target organs. In: Somatic and autonomic nerve-muscle interactions (Burnstock G, O’Brien R, Vrbova G, eds), pp 289-316. Amsterdam: Elsevier.

Gordon T (2009) The role of neurotrophic factors in nerve regeneration. Neurosurg Focus 26:E3.

Gordon T, Tyreman N (2010) Sprouting capacity of lumbar motoneurons in normal and hemisected spinal cords of the rat. J Physiol 588:2745-2768.

Gordon T, Gillespie J, Orozco R, Davis L (1991) Axotomy-induced changes in rabbit hindlimb nerves and the effects of chronic electrical stimulation. J Neurosci 11:2157-2169.

Gordon T, Sulaiman O, Boyd JG (2003) Experimental strategies to promote functional recovery after peripheral nerve injuries. J Peripher Nerv Syst $8: 236-250$.

Guth L, Samaha FJ (1970) Procedure for the histochemical demonstration of actomyosin ATPase. Exp Neurol 28:365-367.

Höke A, Gordon T, Zochodne DW, Sulaiman OA (2002) A decline in glial cell-line-derived neurotrophic factor expression is associated with impaired regeneration after long-term Schwann cell denervation. Exp Neurol 173:77-85.

Jacob JM, McQuarrie IG (1996) Assembly of microfilaments and microtubules from axonally transported actin and tubulin after axotomy. J Neurosci Res 43:412-419.

Li H, Terenghi G, Hall SM (1997) Effects of delayed re-innervation on the expression of c-erbB receptors by chronically denervated rat Schwann cells in vivo. Glia 20:333-347.

Major LA, Hegedus J, Weber DJ, Gordon T, Jones KE (2007) Method for counting motor units in mice and validation using a mathematical model. J Neurophysiol 97:1846-1856.

Mason MR, Lieberman AR, Grenningloh G, Anderson PN (2002) Transcriptional upregulation of SCG10 and CAP-23 is correlated with regeneration of the axons of peripheral and central neurons in vivo. Mol Cell Neurosci 20:595-615.

McPhail LT, Fernandes KJ, Chan CC, Vanderluit JL, Tetzlaff W (2004) Axonal reinjury reveals the survival and re-expression of regenerationassociated genes in chronically axotomized adult mouse motoneurons. Exp Neurol 188:331-340.

Mi R, Chen W, Höke A (2007) Pleiotrophin is a neurotrophic factor for spinal motor neurons. Proc Natl Acad Sci U S A 104:4664-4669.

Michalski B, Bain JR, Fahnestock M (2008) Long-term changes in neurotrophic factor expression in distal nerve stump following denervation and reinnervation with motor or sensory nerve. J Neurochem 105:1244-1252.

Miller FD, Tetzlaff W, Bisby MA, Fawcett JW, Milner RJ (1989) Rapid induction of the major embryonic $\alpha$-tubulin mRNA, T $\alpha 1$, during nerve regeneration in adult rats. J Neurosci 9:1452-1463.

Rafuse VF, Gordon T (1996) Self-reinnervated cat medial gastrocnemius muscles. I. Comparisons of the capacity of regenerating nerves to form enlarged motor units after extensive peripheral nerve injuries. J Neurophysiol 75:268-281.

Rafuse VF, Gordon T, Orozco R (1992) Proportional enlargement of motor units after partial denervation of cat triceps surae muscles. J Neurophysiol 68:1261-1276.

Ramon y Cajal S (1928) Degeneration and regeneration of the nervous system (May RM, translator). New York, Oxford: Oxford UP.

Savolainen J, Myllylä V, Myllylä R, Vihko V, Väänänen K, Takala TE (1988)
Effects of denervation and immobilization on collagen synthesis in rat skeletal muscle and tendon. Am J Physiol 254:R897-R902.

Seijffers R, Allchorne AJ, Woolf CJ (2006) The transcription factor ATF-3 promotes neurite outgrowth. Mol Cell Neurosci 32:143-154.

Sulaiman O, Boyd JB, Gordon T (2005) Axonal regeneration in the peripheral nervous system of mammals. In: Neuroglia (Kettenmann H, Ransom BR, eds), pp 454-466. Oxford: Oxford UP.

Sulaiman OA, Gordon T (2000) Effects of short- and long-term Schwann cell denervation on peripheral nerve regeneration, myelination, and size. Glia 32:234-246.

Sulaiman OA, Gordon T (2003) TGF-beta reverses the deleterious effect of long-term Schwann cell denervation on nerve regeneration by inducing erbB3 receptor expression. Glia 24 [Suppl 2]:60.

Sulaiman OA, Gordon T (2009) Role of chronic Schwann cell denervation in poor functional recovery after nerve injuries and experimental strategies to combat it. Neurosurgery 65:A105-A114.

Sulaiman OA, Midha R, Munro CA, Matsuyama T, Al-Majed A, Gordon T (2002) Chronic Schwann cell denervation and the presence of a sensory nerve reduce motor axonal regeneration. Exp Neurol 176:342-354.

Sulaiman OAR, Midha R, Gordon T (2011) Pathophysiology of surgical nerve disorders. In: Youmans neurological surgery, Chap 233, Ed 6 (Winn HR, ed). Philadelphia: Saunders.

Sunderland S (1978) Nerve and nerve injuries. Edinburgh: Livingstone.

Tam SL, Archibald V, Jassar B, Tyreman N, Gordon T (2001) Increased neuromuscular activity reduces sprouting in partially denervated muscles. J Neurosci 21:654-667.

Tam SL, Archibald V, Tyreman N, Gordon T (2002a) Effect of exercise on stability of chronically enlarged motor units. Muscle Nerve 25:359-369.

Tam SL, Archibald V, Tyreman N, Gordon T (2002b) Tetrodotoxin prevents motor unit enlargement after partial denervation in rat hindlimb muscles. J Physiol 543:655-663.

Terenghi G, Calder JS, Birch R, Hall SM (1998) A morphological study of Schwann cells and axonal regeneration in chronically transected human peripheral nerves. J Hand Surg Br 23:583-587.

Tetzlaff W, Bisby MA, Kreutzberg GW (1988) Changes in cytoskeletal proteins in the rat facial nucleus following axotomy. J Neurosci 8:3181-3189.

Tötösy de Zepetnek JE, Gordon T, Stein RB, Zung HV (1991) Comparison of force and EMG measures in normal and reinnervated tibialis anterior muscles of the rat. Can J Physiol Pharmacol 69:1774-1783.

Tötösy de Zepetnek JE, Zung HV, Erdebil S, Gordon T (1992a) Innervation ratio is an important determinant of force in normal and reinnervated rat tibialis anterior muscles. J Neurophysiol 67:1385-1403.

Tötösy de Zepetnek JE, Zung HV, Erdebil S, Gordon T (1992b) Motor-unit categorization based on contractile and histochemical properties: a glycogen depletion analysis of normal and reinnervated rat tibialis anterior muscle. J Neurophysiol 67:1404-1415.

Veltri K, Kwiecien JM, Minet W, Fahnestock M, Bain JR (2005) Contribution of the distal nerve sheath to nerve and muscle preservation following denervation and sensory protection. J Reconstr Microsurg 21:57-70; discussion 71-74.

Wang LC, Kernell D (2000) Proximo-distal organization and fibre type regionalization in rat hindlimb muscles. J Muscle Res Cell Motil 21:587-598.

Witzel C, Rohde C, Brushart TM (2005) Pathway sampling by regenerating peripheral axons. J Comp Neurol 485:183-190.

Woolf CJ (2001) Turbocharging neurons for growth: accelerating regeneration in the adult CNS. Nat Neurosci 4:7-9.

Xu Q, Midha R, Munro C, Furey M, Gordon T (2003) Prolonged target deprivation reduces the capacity of axotomized motoneurons to regenerate. Soc Neurosci Abstr 28:152.8.

Xu QG, Forden J, Walsh SK, Gordon T, Midha R (2010) Motoneuron survival after chronic and sequential peripheral nerve injuries in the rat. J Neurosurg 112:890-899.

You S, Petrov T, Chung PH, Gordon T (1997) The expression of the low affinity nerve growth factor receptor in long-term denervated Schwann cells. Glia 20:87-100.

Zhao C, Veltri K, Li S, Bain JR, Fahnestock M (2004) NGF, BDNF, NT-3, and GDNF mRNA expression in rat skeletal muscle following denervation and sensory protection. J Neurotrauma 21:1468-1478. 